653 BENZENE AND WORK ON DECK ON PRODUCT TANKERS: EXPOSURES, BENZENE IN EXHALED AIR AND URINARY BIOMARKERS OF BENZENE EXPOSURE

K Forsell ${ }^{*}, G$ Ljungkvist, R Nordlinder, E Andersson, R Nilsson. Occupational and Environmental Medicine, The Sahlgrenska Academy, Gothenburg University, Sweden

\subsection{6/oemed-2018-ICOHabstracts.1114}

Introduction Increased rates of leukaemia have been found among tanker crews. The leukemic carcinogen benzene is a plausible cause, but serving on tankers is not an established risk occupation for leukaemia. Studies on tankers have revealed exposure to benzene, although with inconsistent exposure levels and without toxicological data. We present exposure to benzene together with biomarkers for benzene uptake, metabolism and genotoxic effects on Swedish product chemical tankers.

Methods Between 1995 and 1998, 37 seafarers (20 deck crew members, 17 not on deck) on seven different product chemical tankers, wore personal passive breathing zone dosimeters. Each individual was monitored with timed samples for benzene in end-exhaled (alveolar) air and in urine for unmetabolized benzene, the benzene metabolite $t \mathrm{t}$-muconic acid $(\mathrm{t}, \mathrm{t}-\mathrm{MA})$ and 8-hydroxydeoxyguanosine (8-OHdG), a marker of DNA oxidative stress. Samples were taken before and following a watch for up to 24 hours.

Result The average concentration of benzene in air during a watch (approximately 4 hour) displayed a wide range depending on work task performed (range 0 to $50 \mathrm{mg} / \mathrm{m} 3$; peak $143 \mathrm{mg} / \mathrm{m} 3$ ). All biomarkers were low/undetectable before and elevated after benzene exposure tasks. Peaks for t,t-MA and 8 OHdG occurred after 5 and 13 hours, resp. The time needed for returning to pre-'work task' values were in ascending order alveolar benzene, U-benzene, U-t,t-MA and U-8OdG. Controls had low levels of urinary biomarkers and without diurnal variations.

Discussion Several work tasks resulted in high exposure to benzene, often exceeding the Swedish occupational exposure limit $(1.5 \mathrm{mg} / \mathrm{m} 3,8 \mathrm{hTWA})$. Benzene exposure resulted in oxidative damage to DNA in cells, indicating that work on tankers might induce genotoxic effects in the human body. The finding suggest a plausible mechanism between cause and effect in coherence with epidemiological findings for increased risk of leukaemia in tanker crews.

\section{VARIANCE IN QUARTZ EXPOSURE DURING REPEATED MEASUREMENTS AT SWEDISH FOUNDRIES}

Lena Andersson* ${ }^{*}$ Anders Johansson, Ing-Liss Bryngelsson. Department of Occupational and Environmental Medicine, Örebro University Hospital, Örebro Sweden

\subsection{6/oemed-2018-ICOHabstracts. 1115}

Introduction Today traditional dust measurements are performed during one or at the most two working days and the results will represent the full year exposure. There is a large variation in exposure at a single company during the year depending on a lot of factors, such as production intensity, used Materials and methods, weather conditions, individual work pattern and behaviour. In this study traditional measurements were made during 2 time periods per company and the variance in measurements were studied.

Methods Personal sampling of respirable quartz was performed between April 2015 and February 2016 at one iron foundry and one bronze foundry. The measurements were made two days in a row, twice with two-three months in-between.

The air exposures of respirable quartz as personal measurements were performed for the full work day. A mixed-model was used to study differences between job titles and companies.

Results In total, 66 personal samples of respirable quartz were collected for 21 individuals. The quartz concentrations ranged between $0.0011-0.079 \mathrm{mg} / \mathrm{m}^{3}$.

The mixed-model analysis of respirable quartz show that the job titles and companies differs. Shakeout show a statistical significant increasing odds ratio of 2.4 (95\% CI: 1.06 to 5.33) and the caster and melter has a significant decreasing odds ratio of 0.46 and 0.32 (95\% CI: 0.24 to 0.89 and 0.19 to 0.53$)$ compared to moulder as reference category. The quartz exposures at the iron foundry result in an odds ratio of 2.75 (95\% CI: 1.70 to 4.45$)$ compared to the bronze foundry. Between job titles represent $60.4 \%$ of the overall variance and the between worker within job title variance $25.5 \%$. Discussion The study implies that type of foundry and type of work at the foundry is a greater cause of the variance in the exposure then when in time the measurements are made.

\section{THE IMPACT OF WORKSITE NUTRITION AND PHYSICAL ACTIVITY INTERVENTIONS ON PRODUCTIVITY, WORK PERFORMANCE AND WORK ABILITY: A SYSTEMATIC REVIEW}

A Grimani* ${ }^{*}$ E Aboagye, L Kwak. Karolinska Institutet, Stockholm, Sweden

\subsection{6/oemed-2018-ICOHabstracts.1116}

Introduction Healthy lifestyles play an important role in the prevention of premature death, chronic diseases, productivity loss and other social and economic concerns. The aim of this systematic review is to investigate the impact of worksite dietary and physical activity interventions, focused on environmental and organisational structure, on employees' productivity, work performance and work ability.

Methods A comprehensive literature search in Medline, Cochrane Library and PROPSERO was conducted. Studies were identified from reference lists from all the systematic reviews with resembling objective as in this search and were included if they fulfilled our inclusion criteria. An updated search (2015-2016) in Medline, Embase, Cochrane Library and Scopus, was also conducted. Two or more researchers independently screened abstracts and full-texts for study eligibility as well as assessed risk of bias. Disagreements were resolved by a consensus procedure.

Result A total of 29 randomised control trials and non-randomised controlled studies were included. Nearly thirty percent of the included studies were high quality, while sixty four percent were of medium quality. The studies covered a broad range of multi-level, organizational-level and environmentallevel interventions. Fourteen effective worksite nutrition and physical activity interventions were identified. Seven of these 